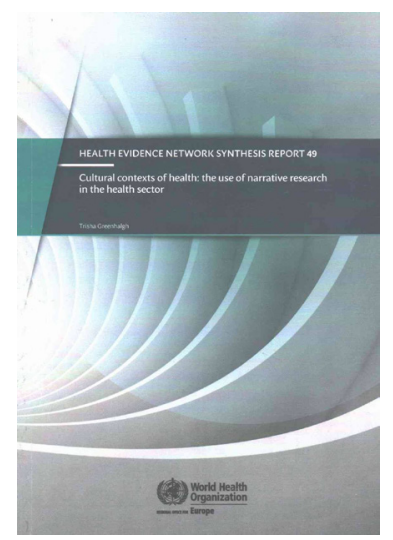

\section{A pesquisa narrativa em saúde}

Em 2003, o Escritório Regional para a Europa da Organização Mundial da Saúde criou um serviço de informação em saúde pública denominado HEN - Health Evidence Network. Baseado em "evidências sintetizadas", propõe "opções políticas" para o desenvolvimento de futuras recomendações na tomada de decisões em saúde. No sentido de programar o plano Saúde 2020, foi realizada uma reunião, em 2015, a fim de discutir como o projeto HEN poderia ser "melhorado por meio de uma maior compreensão dos conteúdos culturais da saúde na região europeia altamente diversificada". Entre as sugestões, figuraram: uso de novos tipos de evidência, pesquisa qualitativa e narrativa, ampliação de disciplinas acadêmicas relacionadas a contextos culturais ${ }^{1}$.

Embora se trate de um Relatório da Região Europeia, a sua aplicação estende-se a outras regiões e situações culturais, por sua originalidade metodológica na pesquisa sobre narrativas, pelos exemplos citados e pelas recomendações feitas. Foi elaborado por Trisha Greenhalgh, Professora de Primary Care Health Sciences, University of Oxford, Reino Unido.
Greenhalgh T. Cultural contexts of health: the use of narrative research WHO Regional Office for Europe; 2016 (Health Evidence Network Synthesis Report 49)1.
Num momento de franco desenvolvimento do campo narrativo em medicina/saúde/adoecimento, o documento reveste-se de especial importância, especialmente porque recoloca a discussão de que "Embora ouvir histórias dos pacientes seja um elemento-chave da medicina clínica, o uso de pesquisas narrativas para melhorar a compreensão de contextos culturais de saúde é mais recente"1 (p. vii).

A ideia básica é responder: como narrativa e cultura se relacionam; como "capturar", pela narrativa, os sistemas de valores e significados partilhados pelos grupos de pessoas, as possibilidades e limites da narrativa no campo da saúde; e como a pesquisa narrativa pode ser utilizada nas políticas de saúde.

Apesar da amplitude das questões propostas, o Relatório sistematiza, de forma didática e com profundidade, questões teóricas, metodológicas e de aplicação.

A abordagem metodológica foi a da "revisão hermenêutica", para pesquisar o uso da narrativa em saúde, pois "uma abordagem abertamente tecnocrática, embora superficialmente rigorosa, poderia ofuscar o processo crítico de interpretação e julgamento". A metodologia baseia-se em Boell e Cecez-Kecmanovic ${ }^{2}$, que partem

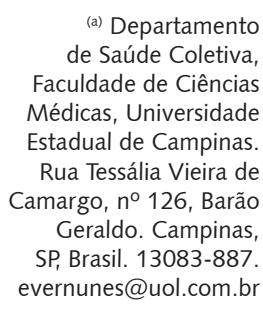

(a) Departamento Faculdade de Ciências Médicas, Universidade Estadual de Campinas. Rua Tessália Vieira de Geraldo. Campinas, SP, Brasil. 13083-887. 
da observação de que "abordagens altamente estruturadas, (à la revisão sistemática), minimizam a importância da leitura e da interação dialógica entre a literatura e o pesquisador; a continuidade interpretativa e questionamento; a avaliação crítica e a criatividade; o desenvolvimento da argumentação e da escrita - atividades altamente intelectuais e criativas, que buscam originalidade ao invés de replicabilidade" (p. 2). Composto por dois momentos - o da busca-investigação e o da análise-interpretação -, trata-se de um processo interpretativo, e não técnico. Seus principais pontos são os seguintes: 1. Início da pesquisa como um quebra-cabeça ou um problema; 2. Busca de textos introdutórios mais gerais e artigos de revisão; 3 . Fase de interpretação dos textos e descoberta de textos adicionais relevantes; 4. Identificação e compreensão das principais ideias, descobertas, conceitos e teorias; 5 . Estabelecimento de conexões entre os achados, teorias, conceitos etc.; 6 . Envolvimento do pesquisador (a) com o material, construindo seu próprio caminho; 7. Questionamento e refinamento das ideias iniciais (p. 47).

Seguindo a metodologia adotada, as fontes bibiliográficas foram identificadas partindo de uma pequena seleção de livros e artigos "amplamente reconhecidos como seminais no campo". São textos das décadas de 1980 (C. Mattingly, C K Kleinman), 1990 (A W Frank, T Greenhalgh, B Hurtwitz), 2000 (C K Riessman, R Charon, $M$ Bury). Na parte referente aos estudos de caso, os exemplos foram também selecionados por meio da "citation pearl searching" estratégia de usar uma publicação relevante para encontrar outras.

Os resultados encontrados foram analisados em duas partes: $1^{\text {a }}$. - métodos narrativos no cuidado à saúde, $2^{\mathrm{a}}$. - exemplos de pesquisa narrativa nos campos da nutrição, do bem-estar e da saúde mental.

Para Greenhalgh, "Uma narrativa (story) é um relato com um começo, uma seqüência de eventos que se desenrolam e um final. A narrativa coloca personagens, eventos, ações e contexto juntos, para dar sentido a eles, e geralmente segue uma forma e um padrão reconhecíveis (por exemplo, romance, mito ou caso clínico)". Destaca que "nenhuma história é uma versão objetiva da verdade"; as histórias são subjetivas e intersubjetivas, "incorporadas em práticas institucionais e sociais", e "convencem não pela sua verdade objetiva, mas por sua semelhança com a vida real e impacto sobre o leitor ou ouvinte". Considera que, se os primeiros autores, como Aristóteles, focalizavam a estrutura (narrativa como substantivo), recentemente, o foco é "mais sobre o ato de contar uma história (narrativa como verbo)" (p. 3,4).

Em seguida, o Relatório destaca uma tipologia de pesquisas narrativas no cuidado à saúde (PNCS): o estudo de caso clínico tradicional; os relatos individuais de adoecimento, obtidos por meio de entrevistas qualitativas; o estudo de caso de narrativas de uma organização ou sistema de cuidado à saúde - contexto institucional da experiência individual do adoecimento e tratamento; narrativas socioculturais que contextualizam histórias particulares de adoecimento; discursos políticos (enquadramentos particulares que motivam a ação ou justificam a inércia); o drama social como estratégia da pesquisa participativa; e as narrativas compartilhadas - as múltiplas vozes das comunidades online e dos movimentos sociais (p. 4).

Os critérios de qualidade para PNCS não diferem daqueles de qualquer pesquisa de alta qualidade: originalidade, clareza e importância do tema a ser pesquisado, adequação do projeto à proposta da pesquisa, amostragem, identificação da unidade de análise, entre outros. Mas, ao apontar que "O rigor na pesquisa narrativa é menos sobre procedimentos técnicos (por ex., que dois observadores independentemente verifiquem os dados) do que produzir interpretação convincente" ( $p$. 5), destaca que a confiabilidade, plausibilidade e criticidade (reflexividade, questionamento e interpretações altenativas) são fundamentais. Salienta o documento que "Contar e interpretar histórias pertence às disciplinas das humanidades e não é uma ciência pura", o que não impede que métodos científicos, como os da linguística, possam ser utilizados. Como procedimentos para garantir critérios científicos à pesquisa, são citados: coletar várias histórias sobre o mesmo assunto, relacionar a história a outras fontes, como dados biomédicos, etc. O que não pode ser marginalizado são os deveres éticos na coleta e uso das histórias: honestidade, consentimento, confidencialidade.

Outro destaque do documento é assinalar que, desde o final de 1990, "A falsa dicotomia 
entre a medicina baseada em evidências e a narrativa foi descartada", e que "pesquisas narrativas bem conduzidas e analisadas podem complementar estudos randomizados, estudos observacionais e dados coletados rotineiramente de vários tipos" (p. 7).

Como pontos positivos da abordagem narrativa, são citados: a construção de significados; não ser linear - "retratar eventos que emergem da interaçao entre ações, relações e contextos"; ser evocativa e memorável; ter um caráter perspectivo - "particulariza a visão de uma pessoa ou grupo cultural"; "capturar um conhecimento tácito"; ser retórica; estar "aninhada dentro de metanarrativas mais amplas"; ter uma dimensão ética; ser aberta - diferentes começos e diferentes fins; ser subversiva, na expressão de Jerome Bruner "Todas as histórias envolvem uma tensão entre o canônico e o inesperado" (p. 7-9).

Entre os aspectos potencialmente limitantes das narrativas, são apontados: "não são verdadeiras em nenhum sentido simples", terem um caráter ficcional, na expressão de Norman Denzin, mas, como já foi assinalado e o texto reforça, "podem ser pensadas em uma visão perspectiva" e não "enviezada"; diferentemente do que ocorre na epidemiologia, onde bias (viez) tem "tons negativos", na pesquisa narrativa, perspectiva tem "tons positivos". Este ponto positivo qualifica a narrativa, pois "permite 0 acesso aos sentimentos de uma pessoa e ao mundo da vida. No entanto, se as histórias pessoais são equiparadas com a verdade, isto empobrecerá a pesquisa" (p. 9).

O documento considera que os contextos institucionais onde as pesquisas são realizadas podem restringir e distorcer as histórias contadas; histórias podem não ser contadas no caso de os indivíduos terem perdido a capacidade de narrar (incapacidade ou demência) ou serem traumatizados pela própria história; falta de treinamento do entrevistador na obtenção das histórias, como limitantes da pesquisa narrativa.

Sobre o uso da pesquisa narrativa - centrada nas pessoas - no âmbito das políticas e do planejamento de saúde, o documento cita: melhorar o conhecimento em saúde dos indivíduos, famílias e comunidades; apoiar o fortalecimento do autocuidado e das redes sociais; dar voz à comunidade; desenvolver uma abordagem holística na formação profissional; promover acessibilidade do cuidado centrado no paciente.

Ponto alto da análise refere-se ao fato de que a evidência narrativa pode ser aplicada tanto no nível individual como no da comunidade, e que os usos mais radicais da narrativa podem incluir membros da comunidade num esquema de pesquisa participativa.

A segunda parte dos achados foi dedicada a analisar a literatura que trata de três estudos de caso: sobre dieta e nutrição, mensuração do bemestar e saúde mental de refugiados, incluindo aqueles que "buscam proteção" (asylum seekers), e suas relações com a cultura. As fontes são estudos de países europeus, e também de outros continentes (América, África e Ásia).

No caso dos estudos sobre nutrição e alimentação, as questões centram-se em alguns pontos como: motivos que levam as pessoas a consumirem determinados alimentos e o que eles significam para elas; como as narrativas ajudam a entender as escolhas dietéticas quando "incorporadas nas práticas culturais"; "explorar os desafios enfrentados quando se procura comer de forma saudável em ambiente obesogênico"; a importância crucial do contexto social (por ex.: restrições religiosas, costumes étnicos, crenças) em sua influência nas escolhas dietéticas. Entre as conclusões dessa revisão de estudos, o documento aponta que "as políticas de saúde pública devem passar de uma abordagem baseada em um modelo (que busca corrigir as supostas deficiências de conhecimento, motivação, etc) a um baseado no encorajamento de alimentos mais saudáveis nas práticas sociais e disponiblizar opções mais saudáveis de alimentos práticos (convenience food)" (p. 15).

Em relação à investigação narrativa nessa área, destacam-se as histórias contadas em um ambiente real (blogs on-line, por exemplo), no sentido de construirem narrativas mais individualizadas sobre a alimentação.

O segundo grupo de estudos de caso aborda a mensuração do bem-estar que, para alguns pesquisadores, é passível de contestação, por ser "um fenômeno inerentemente subjetivo". Esta colocação tem levado, até recentemente, ser uma área "dominada pela métrica quantitativa". Outro debate atual questiona "se o bem-estar é uma característica universal" ou "uma especificidade cultural"; e se "o foco no bem-estar individual desvia-nos de uma análise mais crítica das 
desigualdades estruturais na sociedade". Lembra o documento que a OMS procura complementar índices subjetivos com medidas quantitativas, mas "as evidências narrativas da natureza da experiência de bem-estar" ainda são pouco utilizadas.

Como é assinalado pelos exemplos de diversos contextos culturais, a "Narrativa acrescenta granularidade aos dados da pesquisa" (p. 18). Em um caso - "estudo narrativo de prosperidade precária" - é analisada a situação de uma mulher suíça, nível universitário, com renda mensal acima da média nacional, revelando que essa renda provinha de "trabalhos insatisfatórios, de curta duração e que demandavam viagens e permanência em abrigos temporários", cujos empregos ofereciam poucos ou nenhum direito trabalhista e não levavam em consideração as suas qualificações e experiências profissionais.

Outro exemplo interessante é sobre a pobreza em um país africano, no qual dados qualitativos entre crianças e adultos mostraram como eles classificavam diferentes níveis de pobreza. Verificou-se que os níveis não se referiam "meramente ao valor material e econômico da propriedade e posses (incluindo a propriedade de terras e animais), mas também sobre o valor simbólico e relacional", que se refletiam na "significância cultural da propriedade" (incluindo, por exemplo, a posse de itens particulares de vestimenta) e valorização da autoestima e participação social (p. 18).

Dois outros estudos mostram a enorme possibildade da pesquisa qualitativa narrativa. $O$ primeiro, para explorar o impacto da remoção de minas terrestres por meio de entrevistas e foto-elicitação (uso de imagens para evocar informações) sobre o bem-estar de uma comunidade cambojana. Narrativas antes da remoção relatam estresse psicológico, pela restrição na circulação, de um modo geral, e das crianças, para frequentar as escolas, trabalhar a terra, entre outros. O segundo relata a pesquisa de dois grupos de idosos do Reino Unido (britânicos e imigrantes) e "o uso de tecnologias de assistência para uma vida saudável", também com entrevistas narrativas e foto-elicitação. Foi detectado que "a doença crônica impedia que as pessoas fizessem as coisas que eram importantes para elas e que lhes davam significado e identidade", gerando "sentimentos de perda e desespero", e que as tecnologias usadas "raramente restabele[ciam] essa conexão" (p. 20).

O terceiro grupo de estudos de caso refere-se à saúde mental de refugiados. Trata-se de campo complexo que envolve "um grande número de variáveis que impactam positivamente ou negativamente sobre o processo de aculturação dos migrantes (i.e., integração, assimilação, rejeição ou marginalização)". A proposta de uma "taxinomia de variáveis" inclui: variáveis sociodemográficas (sexo, idade, etnia, religião, etc.); societárias (características da sociedade para a qual migram, se são pluralistas, tolerantes, racistas); do próprio grupo migrante (se são trabalhadores temporários, imigrantes, refugiados, buscando proteção); variáveis sociológicas e psicológicas (experiências anteriores de privações); variáveis comportamentais (acidentes, uso de drogas, álcool, crimes). Segundo o documento, "Estas variáveis, assim como o modo de resolução do processo de aculturação determinarão o grau final de resultados positivos ou negativos quando resolvido o impacto do estresse aculturativo" (p. 21).

O documento aponta que um importante fator que pode levar a problemas mentais entre migrantes é o trauma relacionado a eventos anteriores em seus países de origem ou à própria jornada com uma alta prevalência de estresses psicológicos não específicos e psicopatologias (depressão, ansiedade, esquizofrenia, etc.) (p. 22).

Ressaltam os pesquisadores destas questões a importância das narrativas dos próprios sujeitos que passaram pela experiência de uma migração forçada. Entre as possibilidades metodológicas para a pesquisa narrativa, citam as entrevistas biográficas em profundidade, por exemplo, no caso relatado do estudo de homens jovens vivendo na Noruega, procedentes do norte da África, Oriente Médio e sul da Ásia, que haviam se tornado dependentes de drogas e com tentativas de suicídio, como formas de fugirem de situações intoleráveis. Lembram, os pesquisadores, os desafios que enfrentam quando pesquisam vítimas de opressão, tortura ou violência política, quando as "experiências traumáticas fragmentam a memória, minam a confiança, e inibem a expressão". Situam, também, a questão de que, muitas vezes, as "vozes que se ouvem" não são as dos entrevistados, mas dos pesquisadores.

O documento observa que, no caso de estudos clínicos que "usam a interpretação de narrativas a 
fim de desenvolver teorias", levantam-se questões até onde a pessoa de um médico ou terapeuta é autorizada a advogar para um indivíduo em textos acadêmicos, e a sua legitimidade ou mandato moral para assim fazer. Aspecto interessante é quando "Parcialmente por causa da dificuldade em obter narrativas autênticas na primeira pessoa neste tipo de pesquisa, alguns autores têm usado uma abordagem mais radical, semi-ficcional, para traduzir as experiências dos doentes". Por exemplo, a descrição elaborada pelo Dr. Joseph Achotegui, professor de Psicopatologia na Universidade de Barcelona, de uma nova síndrome - a síndrome de Ulisses - tomando como referência o herói grego "que levou dez anos para voltar ao seu lar, vagando angustiado pelos mares e longe dos seus entes queridos". Achotegui define a síndrome como uma "combinação dos sintomas físicos (por exemplo, insônia, dores de cabeça e cansaço) e psicológicos (por exemplo, alucinações, irritabilidade e ansiedade) experimentada por migrantes que enfrentam múltiplos estressores". Interessante é que "Em vez de explicar os sintomas da síndrome de Ulisses em termos de combinações das variáveis (as pessoas migram, não constroem teorias), Achotegui estabelece paralelos com a história intercultural de Ulisses, cuja identidade é tão profundamente danificada por sua provação" (p. 24-5).
Outras pesquisas que tratam de migrantes que solicitam proteção e das relações com o sistema de saúde são relatadas e trazem importantes reflexões sobre as diferenças culturais nesses momentos, criando dificuldades de comunicação.

Há muitos pontos positivos neste Relatório, não somente pela atualidade do tema - a pesquisa narrativa -, ao adotar uma metodologia original, mas por levantar questões que atravessam a sociedade atual de todos os continentes. A abordagem metodológica de natureza qualitativa, por meio da revisão hermenêutica, "sumariza e sintetiza" evidências, trazendo, para o campo da saúde, especial contribuição ao "completar e ampliar as abordagens tradicionais". Ressaltese que as técnicas poderão variar e ser "usadas ecleticamente e em combinação para capturar contextos culturais" (entrevistas, etnografia, fotoelicitação, etc.).

Ao adotar uma visão holística da saúde e bem-estar e estender a sua compreensão numa interface-indivíduo-cultura-sociedade vai além da realidade exemplificada no texto, podendo ser aplicado às mais diversas sociedades que enfrentam problemas similares, tanto nos processos migratórios (forçados), como nas questões nutricionais, nos processos de adoecimento, quer sejam físicos ou mentais. 
RESENHAS

\section{Referências}

1. Greenhalgh T. Cultural contexts of health: the use of narrative research in the health sector [Internet]. Copenhagen: WHO Regional Office for Europe; 2016 (Health Evidence Network Synthesis Report 49). [citado 4 Abr 2017]. Disponível em: http://www. euro.who.int/_data/assets/pdf_file/0004/317623/ HEN-synthesis-report-49.pdf?ua =1

2. Boell SK, Cecez-Kecmanovic D. A hermeneutic approach for conducting literature reviews and literature searches. Commun Assoc Inform Syst [Internet]. 2014; 34(1):257-86 [citado 4 Abr 2017].

Disponível em: http://aisel.aisnet.org/cais/vol34/ iss $1 / 12$.

Submetido em 28/04/17. Aprovado em 03/05/17. 